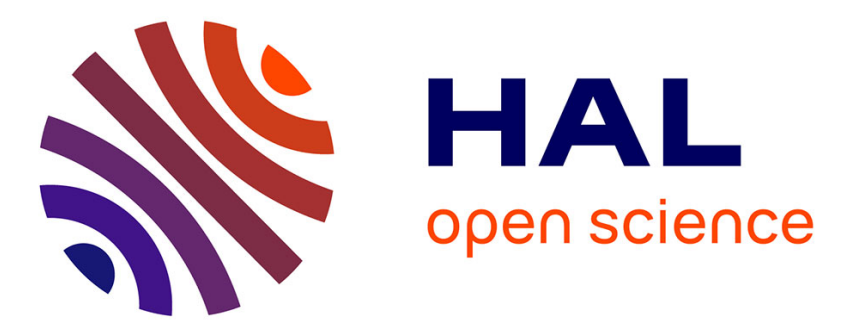

\title{
Towards a Framework for Developing the Emotional Intelligence of Secondary School Students Through the Use of VLEs
}

\author{
Felix Donkor, Rob Toplis
}

\section{- To cite this version:}

Felix Donkor, Rob Toplis. Towards a Framework for Developing the Emotional Intelligence of Secondary School Students Through the Use of VLEs. 11th IFIP World Conference on Computers in Education (WCCE), Jul 2017, Dublin, Ireland. pp.335-345, 10.1007/978-3-319-74310-3_35 . hal01762915

\section{HAL Id: hal-01762915 \\ https://hal.inria.fr/hal-01762915}

Submitted on 10 Apr 2018

HAL is a multi-disciplinary open access archive for the deposit and dissemination of scientific research documents, whether they are published or not. The documents may come from teaching and research institutions in France or abroad, or from public or private research centers.
L'archive ouverte pluridisciplinaire $\mathbf{H A L}$, est destinée au dépôt et à la diffusion de documents scientifiques de niveau recherche, publiés ou non, émanant des établissements d'enseignement et de recherche français ou étrangers, des laboratoires publics ou privés. 


\title{
Towards a framework for developing the emotional intelligence of secondary school students through the use of VLEs
}

\author{
Felix Donkor ${ }^{1}$ and Rob Toplis ${ }^{2}$ \\ ${ }^{1}$ Woolwich Polytechnic School, London, UK \\ ${ }^{2}$ UCL Institute of Education, London, UK \\ fdonkor@woolwichpoly.co.uk
}

\begin{abstract}
Although increasingly schools are using Virtual Learning Environments (VLEs) to teach students and society now understands the importance of Emotional Intelligence, the VLEs currently installed in schools can be said to be 'emotionally unintelligent' and do not help to inspire and encourage students to become emotionally self-aware, empathetic and responsible citizens. Meanwhile, designing a VLE that is emotionally intelligent and consequently responsive to students' emotional and academic needs remains a challenge for both developers and educators. By adopting a process of inductive reasoning, this study draws upon the perceptions of 150 students, 35 teachers and 5 learning support assistants (LSAs) from one secondary school in London (United Kingdom) as well as 2 VLE Content Developers, to propose a framework which, it is argued, can support teachers in helping their students to develop both Emotional Intelligence and academic abilities. Data collection methods used included semi-structured interviews, questionnaires as well as staff and students' focus groups. 5 approaches towards validation (contextbased, theory-based, criterion-related, response and consequential) are used to enhance the credibility of findings. Primarily, this paper aims to stimulate thinking and consequently knowledge that will lead to the design of VLEs that emphasise and capture the emotional dynamics of classrooms and society.
\end{abstract}

Keywords: Emotional Intelligence, VLEs, Secondary schools, Education

\section{Introduction}

This paper seeks to address an emerging area of need, namely Emotional Intelligence in VLEs. Given the increasing use of VLEs and Information and Communication Technologies (ICTs) in classrooms, and the likelihood that such interfaces may well be limited in the qualities of interpersonal relations and group social dynamics compared to those that take place in face-to-face learning environments, the paper argues that increasing attention to aspects such as Emotional Intelligence is a worthy topic in VLE design and implementation. Consequently, the paper shares some insights about how to more effectively combine VLEs and face-to-face learning environments in order to gain the maximum benefits of both.

Since the launch of microcomputers into schools in England in the 1980s, some researchers have observed that there has been continuous introduction of 'new' ICT 
initiatives into school education [1]. Some of these so-called new technologies like interactive whiteboards, digital recorders and voting systems, succeeded to an extent, in reconfiguring classroom practice in some schools [2]. However, it has been argued that in most instances 'money has been spent on ICT on the basis of faith or blind belief in its vocational (and sometimes pedagogical) value, rather than on any basis of evidence' (p. 28) [1]. One of the areas that the VLEs installed in schools fail to explicitly address is how they support or are used to support the development of students' Emotional Intelligence [3][4]. Yet, we now accept that Emotional Intelligence is crucial for cognitive development and also for success in life, as it influences our motivation, resilience and ability to work effectively with others on learning tasks by helping us to keep in check those negative emotions that can distract the learning process [5].

In mathematics education within the secondary school structure of England's education system, for example, we continue to witness the widespread adoption and use of several ICT. It is not uncommon nowadays to see the use of laptops, PCs and tablets in classrooms. In effect, applications, programmes and websites such as the MathsWatch VLE, PiXL MathsAPP, 10 Quick Questions, Mymaths and Live maths amongst others have grown in popularity in mathematics classrooms. Whilst these resources, to a large extent, help in improving outcomes in mathematics for students and schools that have learned to harness their affordances, their very nature promote individualism amongst students. This is because, their use, in most cases, requires students to individually watch video clips and to complete associated tasks. Not much can be said about the power of these resources to encourage students to work collaboratively on tasks, supporting each other on the way and thereby engaging less able or less motivated students. Even the most able or very motivated students could potentially miss out on opportunities to gain deeper understanding about the topic being learnt or the ability to empathise with peers who may be struggling on the same tasks that they may be working on. The sense of isolation and lack of social support associated with such online learning can therefore make the learning process more challenging for students [6] and consequently lead to frustrating and uninspiring experiences for students [7]. More recently, VLEs such as Fronter and Blackboard devoted attention to tools such as whiteboards and shared tasks, intended to support collaboration. Sadly, they too failed to consider how to foster and sustain conditions that support social contexts. In effect, whilst schools may be succeeding in improving academic outcomes for most students, they may also be neglecting opportunities to help students avoid emotionally unintelligent behaviours such as bullying, sarcasm and narcissism, if they do not find new ways of motivating and encouraging students to work collaboratively within the secured learning environments they have installed. Therefore, it is both imperative and critical to study the roles that VLEs can play in helping to develop students' Emotional Intelligence [3]. 


\section{Current study}

\subsection{Context}

This study aimed to build upon previous studies that examined the success factor of using VLEs to support Emotional Intelligence amongst secondary school students [3][4], by identifying a framework that will support teachers and schools in the process. It considered the experiences and views of 35 teachers (10 of whom were key informants and had been purposefully selected because they had previously been identified by their departments as lead teachers with regards to the use of the school's VLE), 5 LSAs and 150 students between the ages of 11-16, all from one school in London. 2 VLE Content Developers were also consulted as part of the study. The perceptions of these participants formed the basis of the proposed framework (Fig. 1) for supporting the development of secondary school students' Emotional Intelligence through the use of VLEs. Hence, it may be argued that the proposed framework has been driven by pedagogy as opposed to technology [7][8].

Due consideration was given to ethical issues throughout the study. For example, it was ensured that informed consent was obtained from the school's leadership and all participants, including anonymity and the right to withdraw at any stage.

\subsection{Procedure}

Ten individual semi-structured interviews were conducted with the 10 key informants during which the following key questions were asked:

1. What does the term Emotional Intelligence mean to you?

2. In what ways do you think the school's VLE should be used in order for it to help in developing students' Emotional Intelligence?

3. Which VLE tools did you trial?

4. In what ways (if any) do you think that the VLE tools trialled encouraged or supported:

i) Reflection

ii) Self-awareness/self-regulation

iii) Empathy

iv) Trust

v) Motivation

vi) Collaboration and relationship management

5. In what ways (if any) did the use of collaborative tools help in

ii) Fostering trust/good relationships?

iii) Establishing a positive classroom ambience in subsequent lessons?

6. Please talk me through any particular observations you made whilst trialling the suggested tools.

7. Is there anything else you would like to ask or add?

Questions 1-5 were used as a guide to maintain the focus of the study. Question 6 was used to encourage critical reflection and to offer interviewees the opportunity to share their experiences and observations in relation to using the VLE tools. Question 7 was to give interviewees the opportunity to ask any other questions pertaining to the study and for them to share their thoughts. 
As a requirement, interviewees were asked to trial the use of at least two of the following VLE tools about a month prior to the interview: forum, videos, test tools or tools for leaving feedback. To improve upon the internal validity of the data collection process, each teacher was provided with a pro forma that highlighted some of the Emotional Intelligence attributes that they were to look out for. For example, they were asked to note down observations in relation to how the use of forums, videos, online testing and feedback impacted on students' self-confidence, selfawareness, motivation to use the VLE, relationship with others online and in class, empathy and trust [3]. The interviewees were consequently given opportunities to talk about their observations during interviews. This included their perceptions of how the VLE tools encouraged reflection, self-awareness/self-regulation, empathy, trust, motivation for learning, collaboration and relationship management. They were also asked about how the use of collaborative tools helped in fostering good relationships and positive classroom ambience in subsequent lessons. Furthermore, answers to the following questions were elicited from 10 focus groups each comprising 5-7 students:

1. How does watching a topic-related video before/after lessons affect your emotions in the classroom?

2. How does topic related-videos provided before/after lessons affect the quality of classroom discussions?

3. Describe how the use of VLE tools such as forums, videos and tests impact on your:

ii) Self confidence

iii) Ability to reflect on tasks

iv) Willingness to join in group discussions

4. How do you feel about the responses offered by your peers in online forums?

5. To what extent does the use of VLE forums and discussion encourage you to become empathetic towards others?

6. Describe ways in which the VLE may be used to foster good relationships.

The study also included staff focus groups at the initial stages to ensure that the concept of Emotional Intelligence is well understood by all staff involved. Staff and student questionnaires were used in the later stages of the study to support or dismiss findings from the interviews and focus group discussions. All questionnaires used in the study were anonymously administered using online survey tools.

\subsection{Validating the current study}

Admittedly, most attributes in educational and social research are not directly observable or measureable. Hence much controversy can be expected to exist about the findings of such studies. To help alleviate doubts about the validity of the approaches to this study as well as conclusions drawn from them, Table 1, adapted from the extant literature [9], was used as a guide to aid the critical examination of key aspects of the study. This ensured that due recognition was given to the validation process and also allowed for more robust conclusions to be drawn.

\begin{tabular}{|l|l|}
\hline Context-based validation & $\begin{array}{l}\text { Are the aims of the research study consistent with its context? } \\
\text { What are the constraints? }\end{array}$ \\
\hline Theory-based validation & $\begin{array}{l}\text { Are the methods chosen supported by the literature? Do all the } \\
\text { tasks that are to be undertaken have sound theoretical basis? In }\end{array}$ \\
\hline
\end{tabular}




\begin{tabular}{|c|l|}
\hline Response validation & $\begin{array}{l}\text { other words, examine what the extant literature says about } \\
\text { Emotional Intelligence in relation to VLEs and how the current } \\
\text { study fits in. Compare findings with existing theory. }\end{array}$ \\
\hline $\begin{array}{c}\text { Use a sample that is representative. Ensure that questions } \\
\text { used/asked are adequate and appropriate - internal validity. } \\
\text { Also, make sure that all questionnaires are piloted. Follow-up on } \\
\text { incomplete responses. Use exploratory interviews to examine } \\
\text { respondents understanding of key terms in order to ensure that } \\
\text { participants are approached from their perspective. By using a } \\
\text { triangulation of methods examine the findings obtained from } \\
\text { using different approaches to see if the different methods are } \\
\text { giving the same responses. Also, ask some key informants to } \\
\text { review draft case study report - construct validity. }\end{array}$ \\
\hline Criterion-related validation & $\begin{array}{l}\text { Do not impose preconceived ideas by using a predefined } \\
\text { framework with which to code the data obtained. Let other } \\
\text { people (at least two) code the same data. Examine whether or not } \\
\text { the same themes arise - if not, probe further - construct validity. } \\
\text { This action should also help in ensuring that the research } \\
\text { approaches and hence its findings are reliable. }\end{array}$ \\
\hline Consequential validation & $\begin{array}{l}\text { Examine the impact of the different tasks on stakeholders. For } \\
\text { example, examine the effect of introducing new characteristics to } \\
\text { the VLE on students'/teachers' motivation to use the VLE. This } \\
\text { may be achieved by for example, comparing the total login } \\
\text { statistics prior to and after embedding into the VLE qualities that } \\
\text { promote Emotional Intelligence. Where possible, directly } \\
\text { observe activities within the VLE. }\end{array}$ \\
\hline
\end{tabular}

Table 1: Showing how validation was ensured in this study

\section{Data analysis}

All interviews were transcribed by one of the researchers in order to enhance familiarity with the data and to ensure that interview transcripts were as accurate as possible. Interview transcripts were subsequently emailed to interviewees so that they could validate them by adding to or taking away from what had been recorded. This represented the most effective means of validating interview data and it ensured that the data used in the analysis represented exactly what the interviewees had intended. The revised interview transcripts were then imported into NVivo 10 software for analysis. The analysis included: identifying the words and ideas that interviewees frequently referred to, coding responses into predetermined categories [3], searching for patterns amongst the codes and building a logical chain of evidence. Focus group data were presented as summaries of each group's discussions as opposed to transcripts of the dialogue that took place. By comparing and contrasting the data obtained from the different focus groups, it was possible to assess if the themes that emerged from one group also emerged from the other groups. Hence, the validity of the strategy was enhanced although this approach also meant that key points raised could not always be traced to the person who made them for clarification. To facilitate analysis, the data collected were coded using the predetermined categories [3]. Staff responses to the questionnaires were initially analysed separately from the students' 
responses. The process involved grouping all answers to a question, reading through answers to open-ended questions to identify common themes and then comparing and contrasting such themes with those that had emerged from the interviews and focus groups.

\section{Results and Discussion}

\subsection{Findings}

The proposed framework (Fig 1) is underpinned by the following findings that resulted from the data analysis of all the data collected in the study:

- VLE tools can be used to facilitate revision and peer-support

- Emotionally intelligent behaviour in class or in a VLE is underpinned by emotional and cognitive maturity

- The ability to give and accept feedback when working within a virtual environment facilitates the development of emotionally intelligent attributes

- Strategic use of VLE tools can promote collaborations and positive relationships, both online and during face to face classroom sessions

- Strategic use of VLE tools can promote self-esteem, self-confidence, selfawareness, self-regulation, motivation and empathy (SSSME)

- Teachers require time and support to successfully develop as well as use VLE tools to meet the needs of students

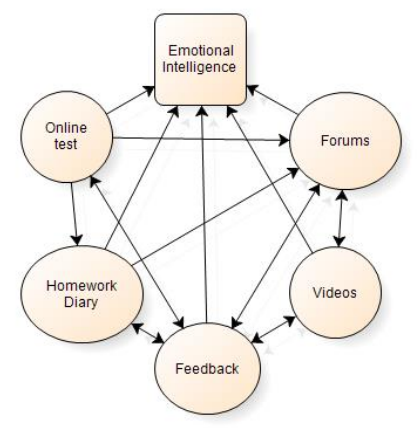

Figure 1: Framework for developing secondary school students' Emotional Intelligence using VLES

\subsection{Explaining the framework}

The framework suggests five inter-related activities that need to underpin the practice of teachers if they are to help their students to develop Emotional Intelligence attributes. The arrows show how the variables are related and the extent to which they depend on each other. Double-ended arrows have been used to show interdependence between variables. It can be seen that there is an arrow pointing to Emotional Intelligence from each of the five variables. This highlights the primary proposal of the framework, developing the Emotional Intelligence of secondary school students 
through the use of VLEs requires the effective use of all the five variables in the model.

It is easily recognisable that the numbers of arrows pointing to the key variables vary. This emphasises two things: Firstly, it shows which other variables that a particular key variable depends on for successful use. Secondly, it gives an indication of the relative importance of a key variable to the framework. In other words, it is being proposed for example, that the use of forums and feedback represent the two most important key variables within the framework. Both are connected by four arrows (to the other key variables), indicating that they support or can be supported by the activities undertaken within the other key variables. What is being illustrated here is that a VLE forum, for example, can be used to provide guidance and support for students as part of the homework they will be required to do. Used this way, students are able to access support from peers and teachers as well as provide support and information to others. This study showed that using VLE forums in this way helps students to develop SSSME. The framework also suggests that a VLE forum should be used to provide a platform for students to support each other with online tests; to discuss issues raised in a video resource; and to provide positive feedback in relation to academic achievements as well as contributions to discussions. This study showed that, used this way, VLE forums allowed students to interact with one another in a friendly manner thereby encouraging them to work well with each other beyond the physical classroom environment. As a consequence, one teacher (anonymous questionnaire respondent) stated that students are encouraged to continue to build their relationships and are in a better position to positively support each other. Another colleague responded during the interview that VLE forums make it possible for students to relate to the opinions of other people 'whom they may not socially mix with in a normal classroom setting'. As a consequence, they suggested that students' ability to empathise and also to interact with such individuals is facilitated. It also emerged that because students know that their opinions are important and that 'everyone else is going to read them' they take time to form such opinions carefully and in the process become more self-aware.

Compared with the setting up of online tests, or the recording, editing and uploading of video resources, using forums and feedback within a VLE are two activities that do not require a lot of effort to set up. Yet they have enormous potential in terms of helping to support Emotional Intelligence development in secondary school students. This point of view found some congruence amongst all the teachers who were interviewed and it was apparent that these represented activities that participants more readily engaged in within the school's VLE. All ten teachers who were interviewed in the current research reported 'immediate' benefits in terms of providing support, starting a discussion, exploring a new topic or providing a platform for expressing opinions. Similar to the findings of this research, some earlier researchers have observed that introducing interactive elements such as VLE forums enables VLE users to communicate and engage interactively with each other [10]. Other research studies, though undertaken within the further education sector, also offer support for the use of forums and feedback in VLEs. For example, an earlier study has shown that opportunities to receive quick feedback from tutors and to use discussion forums represented the most useful VLE components for students [11]. Furthermore, that study reported that $83.33 \%$ of the 108 students who took part in a 
research considered forums as the most useful VLE component whilst $55.56 \%$ opted for learning through feedback [11].

Apart from its connections with the other key variables, the use of feedback in VLEs underpins the successful adoption of every key variable in the proposed framework. This is the reason for placing 'feedback' at the base of the diagram in Fig 1. In other words, the point being projected is that the successful use of feedback in VLEs is the basis upon which the VLE tools proposed can be effectively used to develop students' Emotional Intelligence. For, positive performance feedback yields higher motivation and engagement whereas negative feedback has the propensity of reducing motivation and promoting frustration [12]. Moreover, there is some indication in the extant literature that suggests that the emotionally least skilled benefit not merely from receiving feedback on their Emotional Intelligence, but from receiving it in a way that mitigates their defensiveness and propels them toward constructive development [13].

The absence of a connection (arrow) between videos and online tests in the proposed framework does not suggest that videos cannot be used to support tests or vice versa. The connection is absent because it would be unrealistic to expect teachers to create video resources that related to every test that they put on the VLE. That said analysis of the fieldwork data showed that well-tailored video resources relating to tests, when put on a VLE, can lead to effective revision, successful learning and significant improvements in achievement for most students (see also [3]). This in effect can promote confidence and stir up positive emotions, as well as the motivation to try harder or contribute positively to subsequent classroom discussions [13]. However, the findings of the current study suggested that using VLEs in this way limits students' capacity to discover information for themselves and consequently can reduce their ability to become creative learners.

The primary purpose of the Homework diary within the framework is to ensure that everyone enters and uses the VLE. This is because in schools teachers are supposed to set homework regularly and students are expected to complete such homework. Adopting and enforcing the use of a Homework diary within a school's VLE, therefore, serves as a means of ensuring that teachers and students use the VLE and consequently, are exposed to its affordances as well as other useful resources within it.

\subsection{What are the enablers and inhibitors?}

This study highlighted the fact that for a VLE to be used to support Emotional Intelligence it must first be embraced by its users. This in turn depends on the perceived ease of use of the VLE and how well the user interface supports educational contexts [10][15]. The staff questionnaire showed some congruence with this assertion as $86.2 \%$ of teachers and LSAs indicated that they were encouraged to use the VLE because of its perceived ease of use. Teachers and LSAs also reported that 'access to support' is a major factor that influences their decision to accept and use the VLE. The study brought to light that a poorly planned or presented VLE page one which is difficult for learners to use - is as off-putting as a poorly presented web page or a poorly planned lesson.

It was also noted that the successful use of reflective journals represents another key enabler for using VLEs to support Emotional Intelligence. This is because an 
effective reflective journal enables users to recognise patterns in their work; to consider impacts on their emotions; to establish causal links; and to discriminate between the positive and negative effects of their emotions. With particular reference to the use of forums within the framework, this study showed that that the success of VLE forums depends on students' emotional and cognitive maturity, supervision and the subject matter. The current study found that that if students are using the forum because they are interested, then they will develop positive relationships. On the contrary, one of the key informants highlighted that 'forums can also lead to very negative relationships when students begin to choose between whom to respond to and whom to ignore'.

Similar to observations made by previous researchers [11], findings of the current study revealed that staff workloads; their familiarity with the use of the VLE; and the lack of time to experiment with VLE tools represented the main inhibitors to using the VLE tools proposed. It was apparent also, as with [1] and [16], that user resistance is a crucial inhibitor that needs to be addressed if the proposed framework is to be successfully implemented across a department or school.

\section{Conclusions}

One of the key tenets of the Personal, Social, Health and Economic Education (PSHEE) curriculum in England is that it aims to inspire and encourage students to become kinder, confident, thoughtful and responsible citizens in the communities in which they live. Somehow, these qualities are not fully captured by the technologies that are used to support learning in schools. So, whilst teachers talk to students about the need to develop self-awareness, social awareness and relationship management skills, they unwittingly point the same students in the direction of individualism through the technologies that have been adopted. The current study proposes therefore, that whilst VLEs should be designed to fit around curriculum areas and must be used for teaching and learning, they should enable students to be reflective and to manage relationships. Such collaborative learning opportunities will without doubt, help students to collaborate with their peers on cognitive tasks, to value being part of a group, and also to appreciate the social and interpersonal aspects of learning [12]. The current study has shown that the benefit of helping students to develop their Emotional Intelligence abilities when they work within a VLE transcends that environment. This is because subsequent classroom discussions are likely to be reflective, collaborative and hence more productive. The classroom environment itself can thus be expected to exude calmness and emotional stability, thereby promoting trust, collegiality and the maximisation of students' potential. Indeed, VLEs have come to stay. Therefore, now that they are being used to teach students and schools do understand the importance of Emotional Intelligence, it is imperative and critical to study their efficacy and productivity [3]. The framework proposed in this study represents one way that teachers may use the 'emotionally unintelligent VLEs' currently installed in schools to help students to develop their Emotional Intelligence abilities. However, there may yet be other ways by which educators may manipulate the level of student engagement by intentionally selecting materials and integrating them into the learning process [17]. VLE designers may also have new 
ideas. It is hoped though that this paper helps to stimulate thinking in the areas discussed and thereby offer knowledge that will lead to the design of VLEs that emphasise and capture the emotional dynamics of classrooms and society.

\section{References}

[1] Wellington, J. 'Has ICT come of age? Recurring debates on the role of ICT in education, 1982-2004', Research in Science \& Technological Education, 23(1), 25-39 (2005)

[2] Crook, C. and Cluley, R. 'The teaching voice on the learning platform: Seeking classroom climates within a virtual learning environment', Learning, Media and Technology, 34(3), 199-213 (2009)

[3] Donkor, F. 'Towards emotional intelligence behaviour within virtual learning environments: Perceptions of secondary school teachers', International Journal for $e$ Learning Security, 4(1), 359-365 (2014)

[4] Donkor, F. 'Using VLEs to Support Emotional Intelligence: A Secondary School Perspective', Proceedings of 10th IFIP World Conference on Computers in Education, (Ed. Reynolds, N. and Webb, M.), July 2-5, Torun, Poland, pp. 36-44 (2013)

[5] Goleman, D. Emotional intelligence: Why it can matter more than IQ. London: Bloomsbury Publishing PLC (1996)

[6] Kim, C., Park, S.W. and Cozart, J. 'Affective and motivational factors of learning in online mathematics courses', British Journal of Educational Technology, 45(1), 171-185 (2012)

[7] Hove, M.C. and Corcoran, K.J. 'Educational technologies: Impact on learning and frustration', Teaching of Psychology, 35(2), 121-125 (2008)

[8] Cooper, B. 'The significance of affect in multi-modal communication: lessons for on-line learning', The International Journal of Interactive Technology and Smart Education, Special issue (2006)

[9] Selvaruby, P. S., O‘Sullivan, B. and Watts, D. M. - School-based assessment in Sri Lanka: Ensuring valid processes for assessment-for-learning in physics. In Coll, R. K. and Taylor, N. (eds). Education in context: An international perspective of the influence of context on science curriculum development, Implementation and the studentexperienced curriculum, Sage, London (2008)

[10] Liu, I.-F., Chen, M.C., Sun, Y.S., Wible, D. and Kuo, C.-H. 'Extending the TAM model to explore the factors that affect intention to use an online learning community', Computers \& Education, 54(2), 600-610 (2010)

[11] Limniou, M. and Smith, M. 'Teachers "and students" perspectives on teaching and learning through virtual learning environments', European Journal of Engineering Education, 35(6), 645-653 (2010)

[12] Mullins, D., Deiglmayer, A. and Spada, A. "Shaping Knowledge co-construction” In Baker, M., Andriessen, J. and Je`arvele`a, S. (2013) Affective learning together: social and emotional dimensions of collaborative learning, Routledge, Milton Park, Abingdon, Oxon (2013)

[13] Sheldon, O.J., Dunning, D. and Ames, D.R. 'Emotionally unskilled, unaware, and uninterested in learning more: Reactions to feedback about deficits in emotional intelligence', Journal of Applied Psychology, 99(1), 125-137 (2014)

[14] Stiggins, R. 'From formative assessment to assessment for learning: A path to success in standards-based schools', Phi Delta Kappan, 87(4), 324-328 (2005)

[15] Mueller, D. and Strohmeier, S. 'Design characteristics of virtual learning environments: State of research', Computers \& Education, 57(4), 2505-2516 (2011) 
[16] Shin, D. H., Biocca, F. and Choo, H. "Exploring the user experience of three-dimensional virtual learning environments” Behaviour \& Information Technology, 32(2), 203-214 (2013)

[17] Taylor, S.S. and Statler, M. 'Material matters: Increasing emotional engagement in learning’, Journal of Management Education, 38(4), 586-607 (2013) 